\title{
Colonic Carcinosarcoma: Report of a Rare Colorectal Malignancy and Review of Literature
}

\author{
Melissa Kyriakos Saad ${ }^{\mathrm{a}}$ Fatme Ghandour $^{\mathrm{b}} \quad$ Fatmeh Ghandour El Hajj $^{\mathrm{b}}$ \\ Imad El Hajj ${ }^{\text {a }}$ Elias Saikaly $^{a}$ \\ aGeneral Surgery Department, Saint George Hospital University Medical Center, University of Balamand, Beirut, \\ Lebanon; bPathology Department, Saint George Hospital University Medical Center, University of Balamand, Beirut, \\ Lebanon
}

\section{Keywords \\ Colorectal cancer · Colorectal carcinosarcoma}

\begin{abstract}
Colonic carcinosarcoma is an extremely rare tumor composed of mixed malignant epithelial and mesenchymal cells. Due to its rarity, its pathogenesis is poorly understood, and there are no specific guidelines for its treatment.

(C) 2020 The Author(s)

Published by S. Karger AG, Basel
\end{abstract}

\section{Introduction}

Carcinosarcoma, a biphasic tumor, exhibits epithelial and stromal malignant differentiation. The epithelial component is composed of high-grade or mid-grade adenocarcinoma and the sarcomatous part is of mesenchymal origin which may be differentiated or undifferentiated [1]. Carcinosarcomas can occur in different organs and different anatomical locations; following the first report by Virchow [2] in 1864, its occurrence has been described in various organs. However, a predominance is seen in the female genital tract $[3,4]$, in the head and neck [5], and some isolated reports affecting the gastrointesti-

karger@karger.com www.karger.com/gat

Karger $\stackrel{\text { ' }}{5}$

GOPEN ACCESS
(C) 2020 The Author(s)

Published by S. Karger AG, Basel

This is an Open Access article licensed under the Creative Commons Attribution-NonCommercial-4.0 International License (CC BY-NC) (http://www.karger.com/Services/OpenAccessLicense), applicable to the online version of the article only. Usage and distribution for commercial purposes requires written permission. nal tract, mainly esophagus [6] and stomach [7]. Having said this, colorectal carcinosarcoma is an extremely rare tumor. To the best of our knowledge, 31 cases have been reported as either sarcomatoid carcinoma or carcinosarcoma in the medical literature. Herein, we present a case of cecal carcinosarcoma treated surgically by right hemicolectomy.

\section{Case Report}

A 67-year-old male patient known to have hypertension with no previous abdominal surgeries transferred to our institute for surgical management of large bowel obstruction at the cecum diagnosed by CT scan of the abdomen and pelvis with IV contrast done at another institution showing a $15 \times 15 \mathrm{~cm}$ mass at the level of the cecum with heterogeneous density, with proximal small bowel dilatation, no liver lesions were noted. History goes back to the day of presentation where the patient reported acute onset of abdominal pain in the periumbilical area, non-radiating associated with increase in abdominal girth and inability to pass gas for the last $24 \mathrm{~h}$. Patient reports associated nausea and 2 episodes of biliary vomiting. Patient denies weight loss, blood per rectum, change in bowel habits, and family history of colorectal cancer. Patient also reported that no previous colonoscopy was done. On physical exam, the patient was in pain, with stable blood pressure of 135/80 $\mathrm{mm} \mathrm{Hg}$ and tachycardia of 110 beats per minute. Abdominal exam revealed a distended abdomen, hypoactive bowel sounds, and mild 


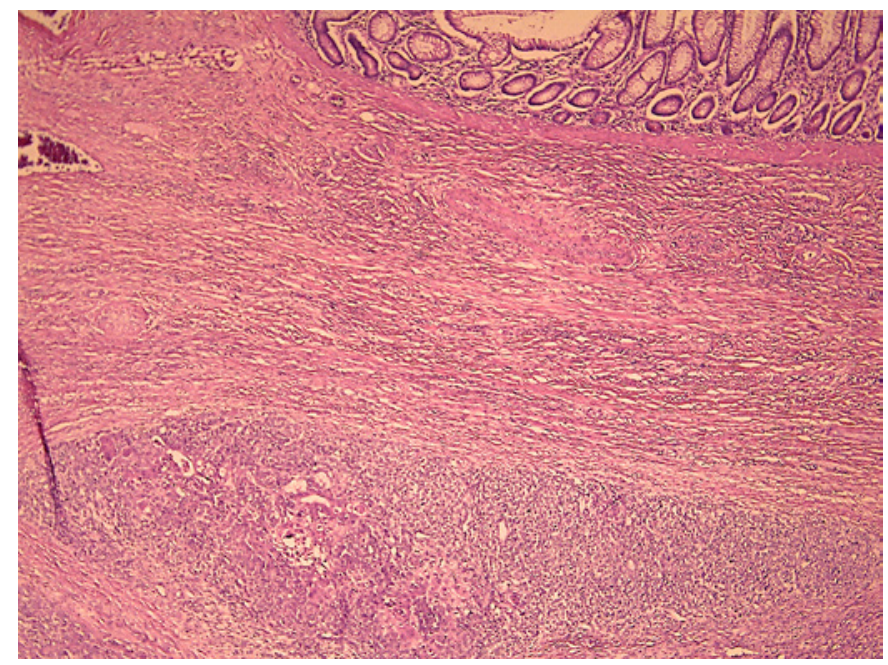

Fig. 1. Tumor with intact overlying bowel mucosa.

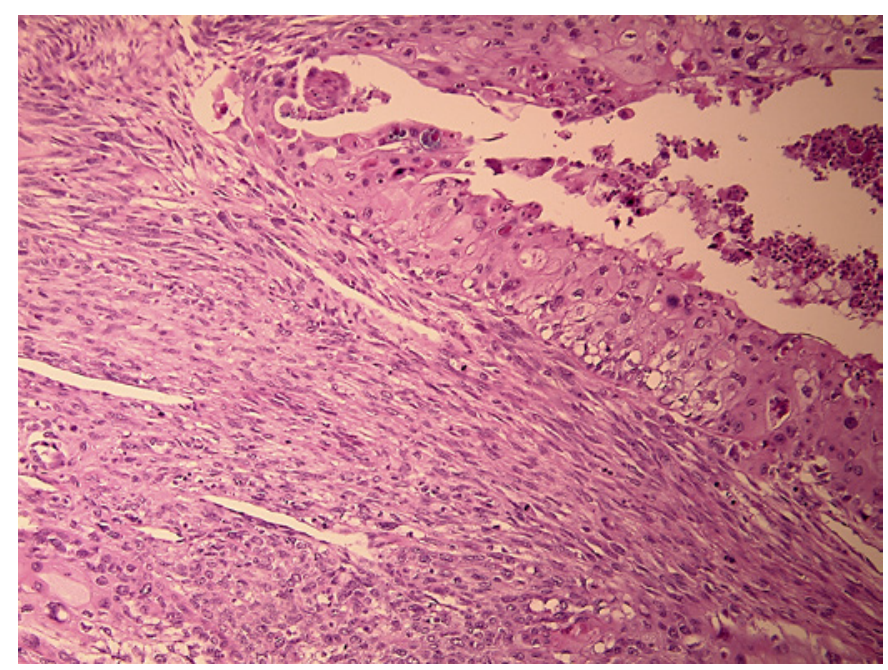

Fig. 3. Higher power magnification showing adjacent squamous and mesenchymal differentiation.

tenderness on deep palpation. Laboratory workup reveals leukocytosis of 17,000 WBC with $80 \%$ neutrophils, elevated inflammatory markers and normal $\mathrm{Cr}$, electrolytes, and amylase. Tumor markers, including CEA and CA 19-9 were normal. Given the above, the patient was diagnosed with mechanical large bowel obstruction and an emergency surgery done. The patient was taken to the operating theater where he was placed in supine position, general anesthesia was given and urinary Foley catheter inserted. Midline laparotomy was done, and abdominal exploration showed no liver deposits and there was no carcinomatosis. A large obstructive mass was observed in the cecum measuring around $10 \mathrm{~cm}$ in diameter and $25 \mathrm{~cm}$ in length, with $20 \mathrm{~cm}$ of the terminal ileum adherent to the colonic mass. Furthermore, a tumorous deposit



Fig. 2. Central and right evident squamous differentiation, with surrounding spindle mesenchymal elements.

was noted at the mesentery of the right colon. Consequently, an oncologic right hemi-colectomy was done, with side-to-side ileocolic anastomosis. Postoperative course was smooth with no complications, and the patient was discharged home on day 6 postsurgery. Histopathology examination of the specimen revealed the following.

\section{Macroscopic Description}

Huge tumor $12 \mathrm{~cm}$ in diameter and $25 \mathrm{~cm}$ in length occupying the ileocecal area with $18 \mathrm{~cm}$ of terminal ileum adherent to the tumor, covered by whitish fibrous adhesions. Opening the specimen revealed a polypoid multilobulated mass occluding the lumen, invading the full thickness of colonic wall reaching the serosal surface. The tumor showed solid white section and glistening mucoid areas and necrosis. A similar-in-appearance 3 -cm nodule was identified at the mesocolon.

\section{Microscopic Description}

Biphasic tumor which in some areas comprised cohesive sheets of polygonal cells having pleomorphic nucleolated nuclei and abundant cytoplasm focally clear and focally dense eosinophilic featuring central keratinization, while in other areas, it showed abundant myxoid stroma with scattered single- and multinucleated cells having markedly pleomorphic nuclei admixed with fascicles of spindle cells having similarly anaplastic nuclei and fibrillary eosiniphilic cytoplasm. Brisk mitotic activity was 


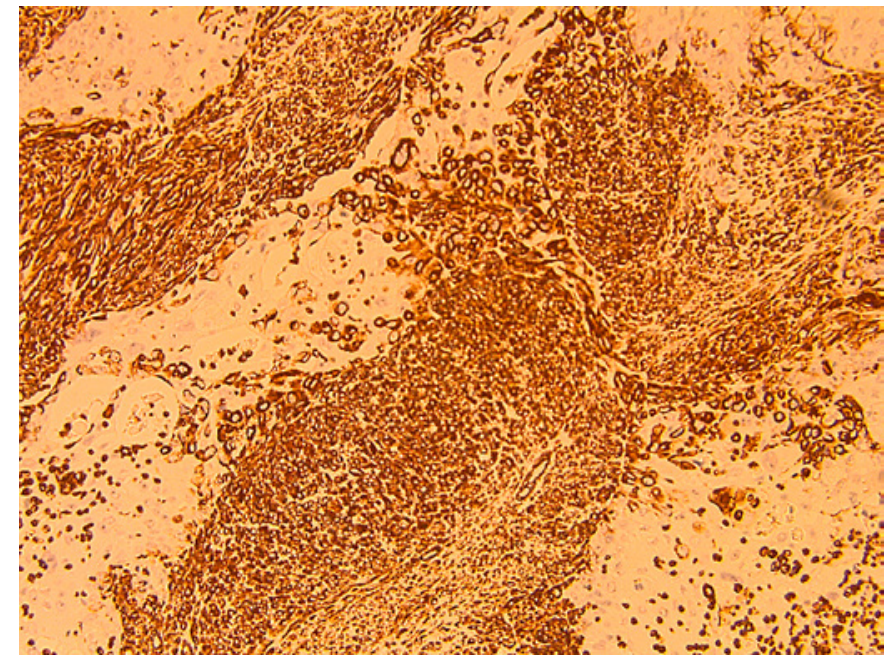

Fig. 4. Vimentin IHC, positive spindle component.

noted throughout. Rare mucin vacuole or glandular lumens were identified among the epithelial elements. Tumor infiltrates the full thickness of the colonic wall till reaching the serosal surface. Lymphatic embolization and absence of vascular invasion was noted. Fibrous adhesions to the terminal ileum with no invasion were observed. One lymph node was positive for malignancy out of $18(1 / 18)$ (Fig. 1-3).

IHC was done and showed prominent delineation between the cell components expressed. Vimentin was positive in mesenchymal, spindle cells (Fig. 4) and cytokeratin in the squamous component (Fig. 5).

\section{Final Diagnosis}

Carcinosarcoma of the cecum with adenosquamous epithelial element and myxoid chondroid and leiomyosarcomatous stromal element with negative margins and 1/18 lymph node positive for malignancy. The patient refused postoperative chemotherapy and was followed up to 1 month after surgery and then lost to follow-up.

\section{Discussion}

Colorectal carcinosarcoma is an extremely rare entity. The first reported case dates back to 1986 by Weidner and Zekan [8], and since then, 31 cases have been reported till date (Table 1) [9, 12-15, 18, 19, 21-25, 30-32, 35-37].

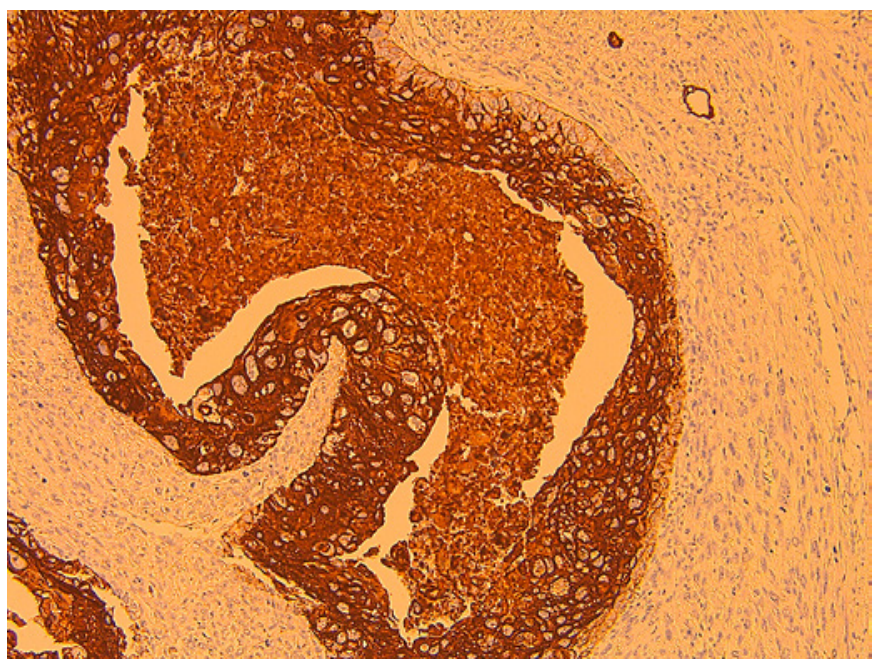

Fig. 5. Cytokeratin IHC, positive squamous epithelial component.

Reviewing the characteristics of the reported cases in the medical literature (Table 2) revealed that the mean age of presentation is 64 years with a range between 13 and 86 years, a male to female ratio of $13: 18$ with $42 \%$ of reported cases being male and 58\% females. Fresh blood per rectum was the most common presenting symptom. The rectum is the most common site of involvement with 9 out of $31(29 \%)$ cases involving the rectum; this is followed by the same number of reported cases involving the ascending colon, descending colon, and the sigmoid colon. The least common site reported to be involved is the transverse colon with only 1 case reported in the medical literature. Only 2 cases have been reported to involve the cecum, and our case is the third cecal involvement to be reported worldwide. Furthermore, what makes our case special is the relatively large size of the tumor when compared to other reported cases.

There's no universal agreement on its nomenclature. Historically, carcinosarcoma has also been known as sarcomatoid carcinoma, carcinoma with mesenchymal stroma, carcinoma with sarcomatous change, spindle cell carcinoma, and pleomorphic anaplastic carcinoma; but the term "carcinosarcoma" is officially used in World Health Organization classification [16].

The histogenesis of carcinosarcoma is poorly understood, and multiple hypotheses have been proposed in an attempt to determine its pathogenesis and its biphasic nature. Regarding gastrointestinal carcinosarcomas, the metaplastic theory is favored, whereby it is believed that the carcinoma component precedes and that it is differ-
10

Gastrointest Tumors 2021;8:8-15 DOI: $10.1159 / 000510628$
Kyriakos Saad et al. 


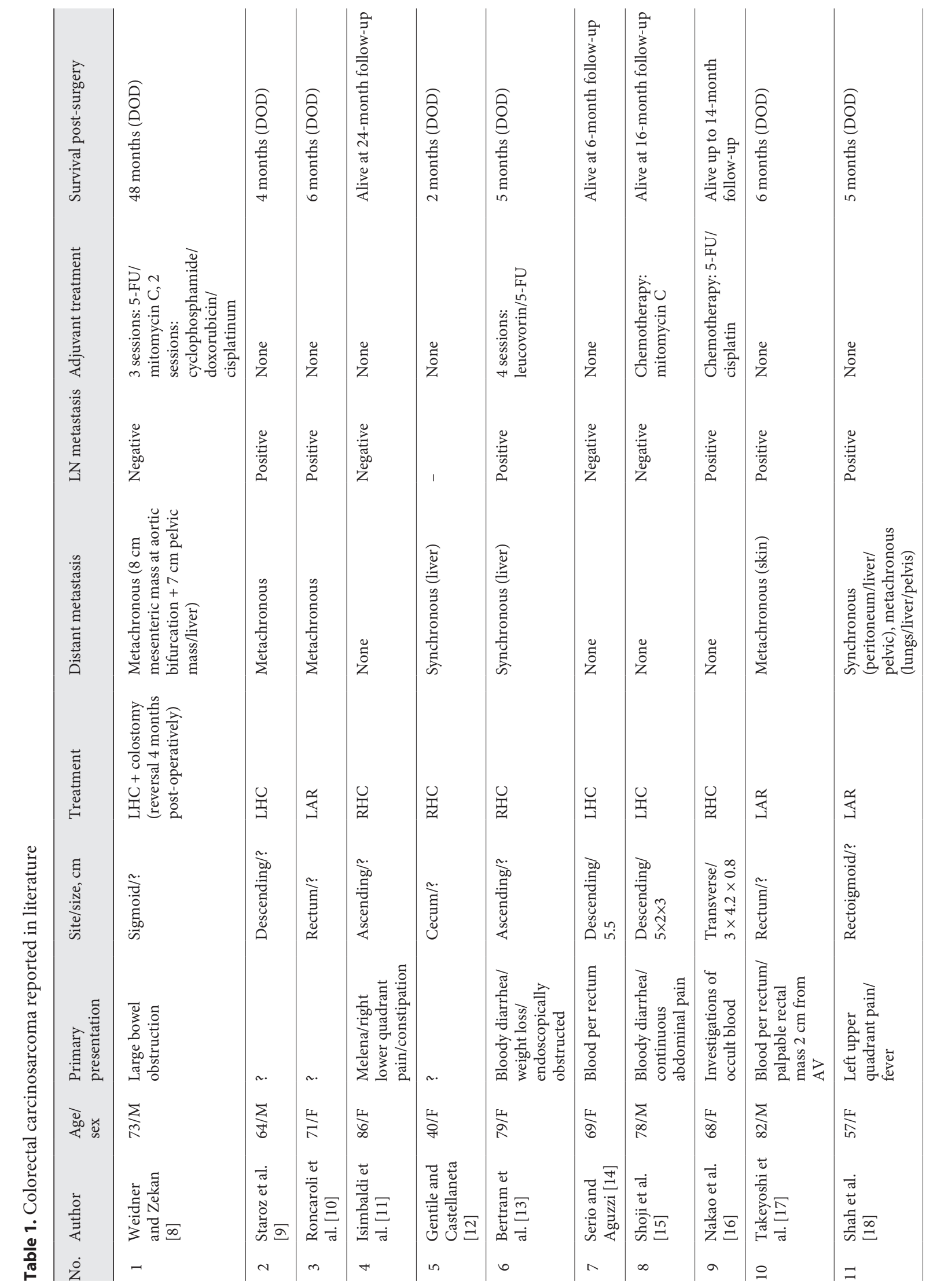




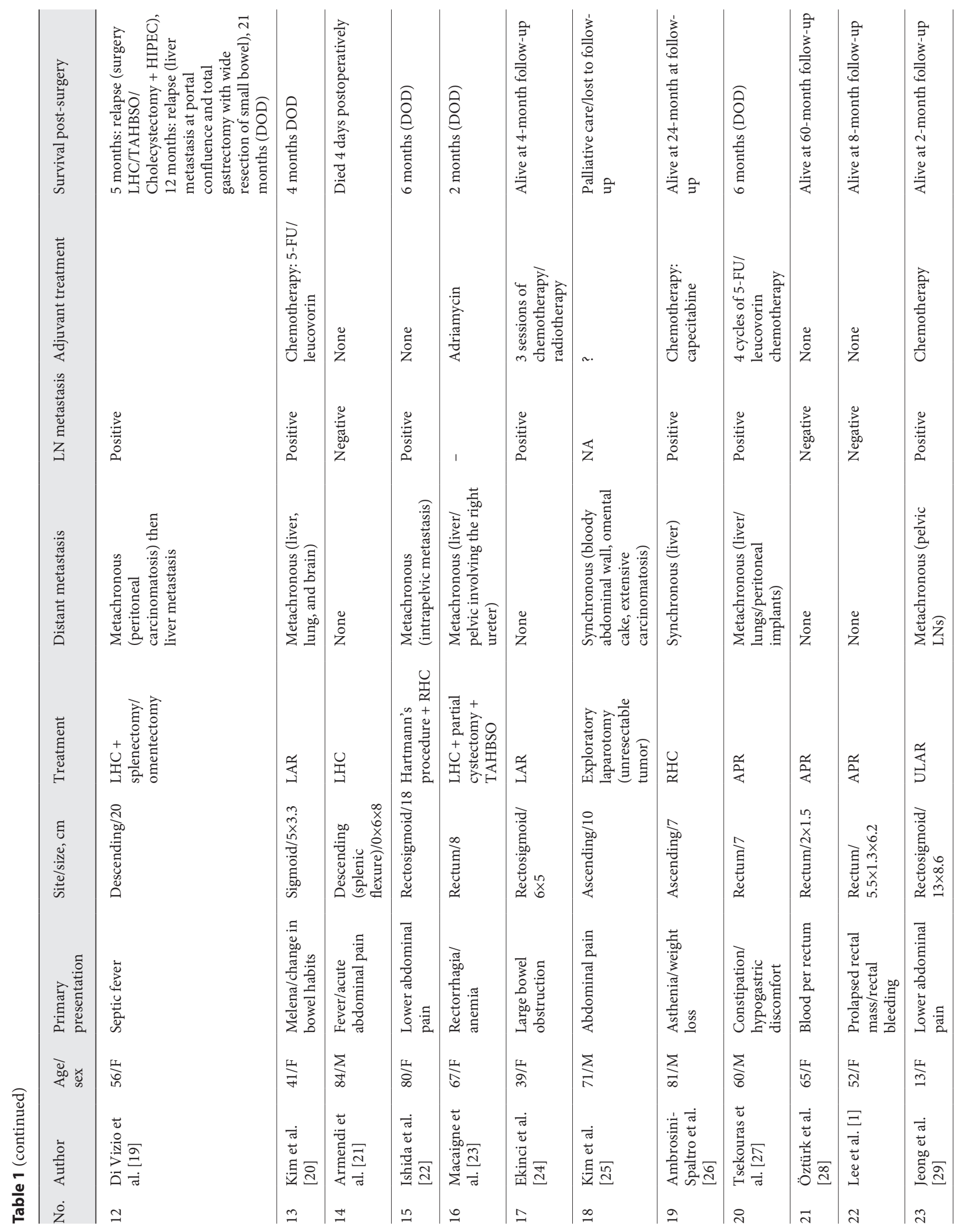




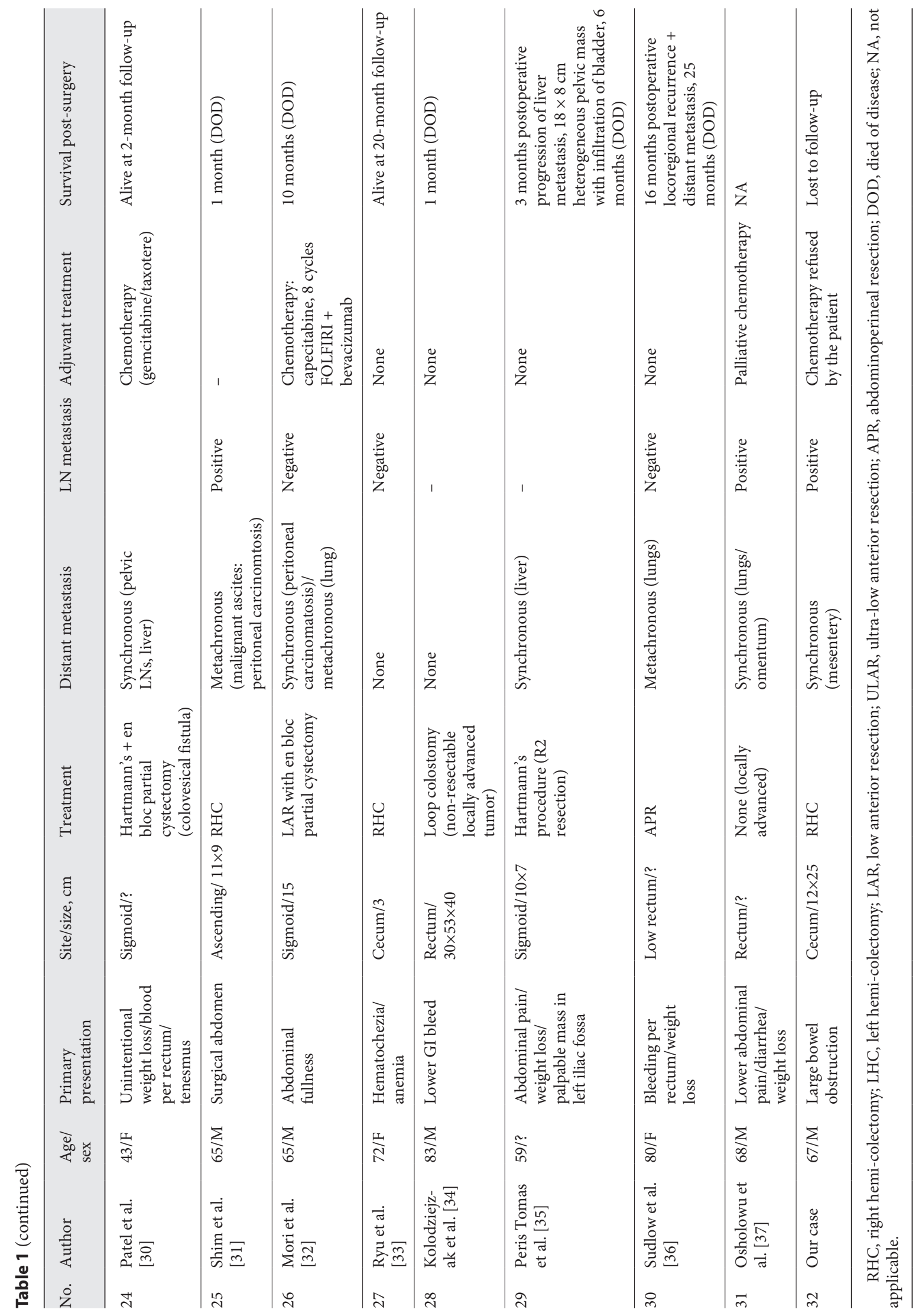


Table 2. Characteristics of reported cases

\begin{tabular}{ll}
\hline Cases reported in the literature, $n$ & 31 \\
\hline Mean age of presentation, range, years & $64(13-86)$ \\
Gender, $n$ (\%) & $13(42)$ \\
Male & $18(58)$ \\
Female & \\
Primary presentation & 2 \\
Large bowel obstruction & 2 \\
Melena & 11 \\
Fresh blood per rectum & 9 \\
Abdominal pain & 3 \\
Diarrhea & \\
Site, $n$ (\%) & $2(7)$ \\
Cecum & $5(16)$ \\
Ascending & $1(3)$ \\
Transverse colon & $5(16)$ \\
Descending & $5(16)$ \\
Sigmoid & $4(13)$ \\
Recto sigmoid & $9(29)$ \\
Rectum & \\
Distant metastasis, $n(\%)$ & $9(29)$ \\
Synchronous & $12(39)$ \\
Metachronous & $10(32)$ \\
No metastasis & 15 \\
Lymph node status & 9 \\
Positive & 12 \\
Negative & 15 \\
Adjuvant chemotherapy & \\
Yes & \\
No & \\
\hline & \\
\hline &
\end{tabular}

entiated into the sarcomatoid component in accordance with the development of cancer clones [38]. Furthermore, it has been also proposed that the phenotype of the carcinoma is converted to a sarcoma due to a viral infection or a mutation of the $\mathrm{p} 53$ gene $[10,11]$. The most commonly observed pattern of staining is reactivity in the adenocarcinomatous component to the epithelial markers, CK20 and CEA $[29,33]$. The sarcomatous cells frequently stain positively for vimentin, desmin, and SMA $[1,8,33]$.

Patients with colonic carcinosarcoma have similar clinical presentation to that of colonic adenocarcinoma. The spectrum of symptoms ranges from rectal bleeding $[1,17,34]$, weight loss [26], abdominal pain [29], and reaching obstructive symptoms [27]. From a surgical point of view, colorectal carcinosarcomas are treated similar to general colorectal cancer; however, given the poor prognosis reported in the medical literature, a more aggressive treatment and closer follow-up is recommended when compared to general colorectal cancer. On the other hand, as colorectal carcinosarcoma is an extremely rare entity, prognostic factors and the optimal adjuvant chemotherapy regimen are yet to be determined. Furthermore, suggested prognostic indicators include size, stage, lymphatic or vascular invasion, and histology of the carcinomatous component [29]. On the other hand, adjuvant therapies, chemotherapy (5-fluorouracil, leucovorin, doxorubicin, and cisplatin), and radiation therapy have been attempted, but their effectiveness has not been proven yet $[16,20,28]$.

The malignant behavior of colorectal carcinosarcoma is very similar to that of adenocarcinoma with the carcinomatous component showing a strong tendency to metastasize to lymph nodes and distant sites, whereas the sarcoma plays only a very minor role in metastatic spread [33]. Having said this, early diagnosis and appropriate oncologic surgery is the cornerstone of successful outcome.

\section{Conclusion}

Colorectal carcinosarcoma is a biphasic tumor, exhibiting epithelial and stromal malignant differentiation. Immunohistochemistry is the gold standard for diagnosis. Due to its rarity, no specific treatment guidelines exist, and its treatment depends solely on the previously described case reports, which suggest treating colorectal carcinosarcoma in a similar fashion to colorectal adenocarcinoma. Further studies and collection of cases are needed to establish proper therapeutic guidelines.

\section{Acknowledgement}

The authors acknowledge the general surgery department at Saint George Hospital University Medical Center.

\section{Statement of Ethics}

Written informed consent was obtained from the patient to publish the case as well as all the images.

\section{Conflict of Interest Statement}

No conflict of interest by all authors.

\section{Funding Sources}

No funding was received for this article.
Kyriakos Saad et al. 


\section{Author Contributions}

Melissa Kyriakos Saad wrote the article and did the review of literature. Elias Saikaly wrote the article and did the review of literature. Fatme Ghandour wrote the pathology section and pre- pared the slides. Fatmeh Ghandour El Hajj wrote the pathology section and prepared the slides. Imad El Hajj reviewed the article and the literature.

\section{References}

1 Lee JK, Ghosh P, McWhorter V, Payneau M, Olsonau R, Krinskyau ML, et al. Evidence for colorectal sarcomatoid carcinoma arising from tubulovillous adenoma. World J Gastroenterol. 2008;14(27):4389-94.

2 Virchow R. Die krankhaften Geschwulste. Berlin: Hirschwald; 1864. p. 170-384.

3 Baiocchi G, Kanavagh JJ, Wharton JT. Endometrioid stromal sarcomas arising from ovarian and extraovarian endometriosis. Report of two cases and literature review. Gynecol Oncol. 1990;36:147-51.

4 Norris HJ, Taylor HB. Mesenchymal tumors of the uterus: III. A clinical and pathologic study of 31 carcinosarcomas. Cancer. 1966; 19:1459-65.

5 Berthelet E, Shenouda G, Black MJ, Picariello M, Rochon L. Sarcomatoid carcinoma of the head and neck. Am J Surg. 1994;168(5):4558.

6 Madan AK, Long AE, Weldon CB, Jaffe BM. Esophageal carcinosarcoma. J Gastrointest Surg. 2001;5(4):414-7.

7 Tsuneyama K, Sasaki M, Sabit A, Yokoi K, Arano Y, Imai T, et al. A case report of gastric carcinosarcoma with rhabdomyosarcomatous and neuroendocrinal differentiation. Pathol Res Pract. 1999;195(2):93-8.

8 Weidner N, Zekan P. Carcinosarcoma of the colon. Report of a unique case with light and immunohistochemical studies. Cancer. 1986; 58(5):1126-30.

9 Staroz F, Botton A, Potet F. Malignant tumors of the colon with two components (carcinosarcoma): report of a case. Ann Pathol. 1995; $15: 457-8$.

10 Roncaroli F, Montironi R, Feliciotti F, Losi L, Eusebi V. Sarcomatoid carcinoma of the anorectal junction with neuroendocrine and rhabdomyoblastic features. Am J Surg Pathol. 1995;19(2):217-23.

11 Isimbaldi G, Sironi M, Assi A. Sarcomatoid carcinoma of the colon: report of the second case with immunohistochemical study. Pathol Res Pract. 1996;192(5):483-7.

12 Gentile R, Castellaneta A. Carcinosarcoma of the colon, one or two tumors? Pathologica. 1997;89:62-8.

13 Bertram P, Treutner KH, Tietze L, Schumpelick V. True carcinosarcoma of the colon: case report. Langenbecks Arch Chir. 1997;382(3):173-4.
14 Serio G, Aguzzi A. Spindle and giant cell carcinoma of the colon. Histopathology. 1997; 30(4):383-5.

15 Shoji M, Dobashi Y, Iwabuchi K, Kuwao S, Mikami T, Kameya T. Sarcomatoid carcinoma of the descending colon: a histological, immunohistochemical and ultrastructural analysis. Acta Oncol. 1998;37(7-8):765-8.

16 Nakao A, Sakagami K, Uda M, Mitsuoka S, Ito $\mathrm{H}$. Carcinosarcoma of the colon: report of a case and review of the literature. J Gastroenterol. 1998;33(2):276-9.

17 Takeyoshi I, Yoshida M, Ohwada S, Yamada T, Yanagisawa A, Morishita Y. Skin metastasis from the spindle cell component in rectal carcinosarcoma. Hepatogastroenterology. 2000;47(36):1611-4.

18 Shah S, Kim DH, Harster G, Hossain A. Carcinosarcoma of the colon and spleen: a fleshy purple mass on colonoscopy. Dig Dis Sci. 2001;46(1):106-8.

19 Di Vizio D, Insabato L, Conzo G, Zafonte BT, Ferrara G, Pettinato G. Sarcomatoid carcinoma of the colon: a case report with literature review. Tumori. 2001;87(6):431-5.

20 Kim JH, Moon WS, Kang MJ, Park MJ, Lee DG. Sarcomatoid carcinoma of the colon: a case report. J Korean Med Sci. 2001;16(5): 657-60.

21 Aramendi T, Fernández-Aceñero MJ, Villanueva MC. Carcinosarcoma of the colon: report of a rare tumor. Pathol Res Pract. 2003; 199(5):345-8.

22 Ishida $\mathrm{H}$, Ohsawa T, Nakada H, Hashimoto D, Ohkubo T, Adachi A, et al. Carcinosarcoma of the rectosigmoid colon: report of a case. Surg Today. 2003;33(7):545-9.

23 Macaigne G, Aouad K, Boivin JF, Bellaïche A, Auriault ML, Picard D, et al. Sarcomatoid carcinoma of the colon: report of a case and review of the literature. Gastroenterol Clin Biol. 2004;28:600-4

24 Ekinci N, Ergun SA, Kar H. Sarcomatoid carcinoma of the colon. Turk J Cancer. 2005;35: 138-40.

25 Kim N, Luchs JS, Halpern D, Davis E, Donovan $\mathrm{V}$, Weston SR, et al. Radiology-pathology conference: carcinosarcoma of the colon. Clin Imaging. 2005;29(4):259-62.

26 Ambrosini-Spaltro A, Vaira V, Braidotti P, Rovati MP, Ferrero S, Bosari S. Carcinosarcoma of the colon: report of a case with morphological, ultrastructural and molecular analysis. BMC Cancer. 2006;6:185.
27 Tsekouras DK, Katsaragakis S, Theodorou D, Kafiri G, Archontovasilis F, Giannopoulos P, et al. Rectal carcinosarcoma: a case report and review of literature. World J Gastroenterol. 2006;12(9):1481-4.

28 Öztürk E, Yilmazlar T, Yerci O. A rare tumor located in the anorectal junction: sarcomatoid carcinoma. Turk J Gastroenterol. 2006;17: 236-9.

29 Jeong YJ, Lee MR, Kim JC, Hwang PH, Moon WS, Chung MJ. Carcinosarcoma of the rectosigmoid colon in a 13-year-old girl. Pathol Int. 2008;58(7):445-50.

30 Patel DH, Dang S, Bentley FR, Julka RN, Olden KW, Aduli F. Carcinosarcoma of the colon: a rare cause of colovesical fistula. Am Surg. 2009;75(4):335-7.

31 Shim HJ, Hong YK, Kim SJS, Choi YJ, Kang JG. Carcinosarcoma on ascending colon found by bowel perforation: a case report. J Korean Soc Coloproctol. 2010;26(5):368-72.

32 Mori Y, Katsumata K, Suzuki S, Matsudaau D, Haraau T, Hayashidaau Y, et al. Carcinosarcoma of the sigmoid colon: report of a case. Case Rep Gastroenterol. 2010;4(3):484-91.

33 Ryu Y, Kim A, Kim H, Lee BJ, Jung W. Carcinosarcoma in the cecum. Gut Liver. 2012; 6(3):395-8.

34 Kołodziejczak M, Bielecki K, Sudoł-Szopińska I, Szcześniakau A, Obcowskaau A. Very rare case of rectal carcinosarcoma. Tech Coloproctol. 2013;17(5):615-7.

35 Peris Tomas N, Lozano AG, García RM, Ortega GG, Abad MM. Carcinosarcoma de colon: a propo' sito de un caso. Cir Esp. 2013;91:623.

36 Sudlow A, Liu MH, Waters G, Velchuru VR. Carcinosarcoma of the rectum: report of a rare colorectal malignancy and review of the literature. Case Rep Surg. 2015;2015:4129184.

37 Osholowu O, Reisdorf C, Hall D, Kak V, Gupta $\mathrm{V}$. A rare case of sarcomatoid tumor of the colon: 1409. Am J Gastroenterol. 2017;112: S763.

38 Matsumoto T, Fujii H, Arakawa A, Yamasakiau S, Sonoueau H, Hattoriau K, et al. Loss of heterozygosity analysis shows monoclonal evolution with frequent genetic progression and divergence in esophageal carcinosarcoma. Hum Pathol. 2004;35(3):322-7. 